This is a post-print version of 'Smakman D. (2018), Het Nederlandse fonologiegedeelte van Taalportaal,

Nederlandse Taalkunde 23(2): 117-127.', originally published by Amsterdam University Press.

\title{
Het Nederlandse fonologiegedeelte van Taalportaal
}

Dick Smakman

\begin{abstract}
The Taalportaal website is a highly accessible webpage for those interested in Dutch, Afrikaans, and Frisian. The Dutch Phonology part can be used by both researchers and teachers. Both groups, however, might be confused by certain transcription conventions, because underlying principles are not explained. Language variation and social connotations also deserve more attention. In general, explanations might be added, so that pronunciation theory and actual usage become less conflated.
\end{abstract}

Keywords: phonology, transcription, pronunciation, language variation, language norms

\section{Inleiding}

De Taalportaal-website levert een belangrijke bijdrage aan het verspreiden van kennis van het Nederlands, Fries en Afrikaans voor een internationaal taalkundig publiek. Het geeft een uniek overzicht van deze drie talen en put daarbij uit bestaande gezaghebbende bronnen. De Nederlandse fonologiepagina's laten een duidelijk overzicht zien, opgedeeld in klinkers en medeklinkers. Verder kom je meer te weten over Phonotactics, Phonological processes, Phonology-Morphology interface, en bijvoorbeeld prosodische processen. In deze bespreking beperk ik me vooral tot het Segment inventory-gedeelte. Sommige van de opmerkingen hebben hun weerslag op de andere gedeeltes.

\section{Verantwoording van transcriptiekeuzes}

Het Segment inventory-gedeelte over het Nederlands geeft duidelijke uitleg en voorbeelden van klanken en houdt rekening met het effect van fonetische en fonologische context en van onderliggende vorm. In de keuzes die zijn gemaakt, zijn enkele principes actief die niet iedere internationale lezer direct zal begrijpen. Het is dan aan te raden dat duidelijk te maken voorafgaand aan de transcripties.

Een voorbeeld is de transcriptie van stem in coda-obstruenten. Voor /d, b, z/ wordt uitgelegd hoe deze in codapositie verstemloosd zijn. Het woord hand wordt getranscribeerd als /hand/ en [hant] en verstemlozing wordt als reden genoemd voor deze verschillen tussen 
de fonemische en allofonische typering. Over /p/ wordt vermeld dat het "clearly is the voiceless counterpart of /b/. Final devoicing of the latter segment renders [p]'. Voor coda /z/ wordt dit devoicing-principe ook toegepast.

Ten grondslag aan deze transcriptiekeuzes ligt een principe dat door niet-theoretisch taalkundigen niet direct herkend zal worden, namelijk dat onderliggende vormen in fonemische transcripties verwerkt worden zonder dat deze in werkelijke spraak hoorbaar hoeven te zijn. De stemloze klank is in dit geval een afgeleide van de stemhebbende. Een andere gebruikelijke manier om IPA-transcriptie toe te passen is door aannames over onderliggende vormen niet leidend te laten zijn en fonemische en fonetische transcripties te zien als twee maten van uitspraakdetail op basis van werkelijke uitspraak, zoals men in de sociolinguïstiek vaak ziet. Het jammerlijke van het systeem dat in Taalportaal gebezigd wordt, is dat een buitenstaander die niets weet over de Nederlandse taal zou kunnen denken dat een woord als hand, indien rustig uitgesproken, met een stemhebbende klank kan eindigen en slechts in context een stemloze klank in die positie heeft.

De principes die in het fonologische gedeelte van Taalportaal worden gemaakt, doen denken aan de beschrijvingen die Abercrombie (1964) en Gussenhoven (2007) geven voor een 'systematic' transcriptie, en niet aan de beschrijving van een 'impressionistic' transcriptie, die dezelfde auteurs geven. In Taalportaal kan uitgelegd worden dat meervoudsvormen en/of infinitieven als de basis worden gezien (handen, lezen) in fonemische transcripties, wellicht, en waarom daarvoor gekozen is. Of misschien is een eerdere of algemenere vorm, mogelijk de Middelnederlandse of Algemeen West-Germaanse, gebruikt als basis? Uitleg kan worden gegeven over in welke gevallen principes van onderliggende structuren worden toegepast en waar die principes hun grondslag hebben.

Aansluitend op het bovenstaande is de suggestie dat werkelijke uitspraak een vastere plaats krijgt op de website, in plaats van deze informatie zo nu en dan te geven. Taalportaal geeft aan dat veel mensen de talen die op deze website worden beschreven als tweede taal aanleren, en daarop aansluitend zou de website per klank expliciet kunnen aangeven hoe de dagelijkse uitspraak is, en ook allerlei variationistische onderzoeksbevindingen (die beschikbaar zijn, veelal in het Engels) zouden een plek kunnen krijgen. Op die manier zouden leerders het verschil te weten komen tussen achterliggende structuur, taalnorm en werkelijke uitspraak; de variatie die daarin gebruikelijk is. Zo'n extra gedeelte kan gevuld worden met de nog wat losse opmerkingen die nu al op Taalportaal staan, aangevuld met - onder andere thema's als onderstaande. 


\subsection{Diftongering}

In Taalportaal wordt het klinkerdiagram van Gussenhoven (1992) gebruikt voor het Nederlands. In dit diagram wordt het licht diftongische karakter erkend van wat vaak de lange middenvocalen van het Nederlands worden genoemd (Kloots 2008), namelijk /e, o, ø/. Ze worden in genoemd diagram beschreven als minder diftongisch dan de diftongen / $\varepsilon$ i, œy, au/. Onderzoek van Van de Velde (1996), Adank, Van Hout \& Smits (2004) en Smakman (2006), waarin akoestische en perceptieve beschrijvingen van deze klanken in de uitspraak van sprekers van de normtaal in Nederland en Vlaanderen te vinden zijn, laat een genuanceerd beeld zien van mate van diftongering. De data van Van de Velde (1996) suggereren bijvoorbeeld dat de /e/ en de /o/ door sprekers van de normtaal in Nederland meer diftong dan monoftong kunnen zijn. Er zijn ook indicaties dat er systematische verschillen zijn tussen deze drie vocalen onderling in mate van diftongering (De Vooys 1946, Smakman 2006, Van de Velde 1996, Zwaardemaker \& Eijkman 1928). De data van Smakman (2006) laten zien dat de diftongering van de /o/ in mate van tongbeweging vergelijkbaar is met die van /عi, œy, au/. (Interessant detail is ook dat Van de Veldes data laten zien dat voor de /e/ en /o/ de Vlaamse sprekers van de normtaal in zijn corpus geen enkele neiging tot diftongering laten zien waardoor het vermelden van verschillen tussen twee uitspraaknormen een belangrijke aanvulling lijkt). De effecten van /l/ op de tongbeweging binnen voorgaande klinkers verdienen ook meer aandacht (Botma, Sebregts \& Smakman 2012) en hetzelfde geldt voor het effect van $/ \mathrm{r} /$ op tongbeweging. De mogelijk toenemende verlaging van het eerste element van /عi, œy, au/ in de normtaal in Nederland (Smakman 2006, Stroop 1998) is ook relevante informatie die gemeld kan worden.

\subsection{Fricatieven}

Het gedrag van fricatieven /v, z/ in verschillende contexten verdient meer aandacht. De verschillen in mate van verstemlozing - de relatieve verstemlozing en ook veranderingen in de tijd (vroeger versus meer recentelijk) - en de sociale connotaties die hierbij actief zijn, kunnen worden beschreven middels Gussenhoven (1981a, 1981b), Van der Wal \& Van Bree (2008), Smakman (2006) en Van de Velde (1996). De auteurs in Taalportaal verwijzen overigens al regelmatig naar zulke en andere bronnen, maar geven deze informatie de vorm van bijzaken.

In bovenstaande en andere bronnen wordt ook de variatie in het gebruik van $g$ vermeld. Taalportaal geeft momenteel aan dat deze klank fonemisch getranscribeerd dient te worden als velair, dus als /x/ en/of / $/$ /. Echter, vermeld wordt niet dat de meer uvulaire 
realisaties dominanter aan het worden zijn in Nederland. De opmerking dat de stemhebbende variant als wel de velaire realisatie zelfs in toenemende mate gemarkeerd zijn in Nederland (Mees \& Collins 1982, Smakman 2006) kan gemaakt worden. De uvulaire realisatie van de $g$ in de normtaal in Nederland is al oud (Bilderdijk 1826, Van Haeringen 1924), en meer recentelijk heeft onderzoek (Van de Velde 1996, Smakman 2006) duidelijk gemaakt dat die realisatie in Nederland dichter bij de norm ligt dan de inmiddels gemarkeerde velaire realisaties. Ook de toenemende schraperige klank die bij uvulaire realisaties vaak komt kijken in Nederland (Van de Velde 1996, Smakman 2006) is relevant. (De zuidelijke normtaal lijkt eerder tegen veel van deze tendensen in te gaan.) Verder zou vermeld kunnen worden dat in het verleden stemhebbende en stemloze varianten van de $g / c h$ naast elkaar bestonden, systematisch verdeeld over contexten, en dat overblijfselen van dat systeem mogelijk nog bestaan voor sommige sprekergroepen. Ook de /h/-achtige realisatie van $g / c h$ in sommige Vlaamse dialecten verdient aandacht.

\subsection{Medeklinker ' $r$ '}

Ook opmerkingen als '[i]mportant variants of Dutch /r/ have a uvular place of articulation' kunnen in een aparte tekst over variatie binnen het Nederlandse taalgebied geplaatst worden in plaats van als weetje te worden gepresenteerd. Sebregts (2014) en Smakman (2006) geven uitgebreide beschrijvingen van de aanzienlijke fonetische en sociale variatie binnen de taalnorm en daarbuiten van zowel coda $r$ als onset $r$.

\subsection{Assimilatie}

Opmerkingen over assimilatie - onder andere dat zakdoek uitgesproken kan worden als za[gd]oek en de opmerking dat handzaam fonemisch han/dz/aam is en allofonisch han[ts]aam - verdienen meer expliciete aandacht; onder welke taalkundige en sociale omstandigheden vindt dit plaats en hoe frequent is het? Ook de onderbouwing van deze soms wat overtuigd gebrachte opmerkingen verdient aandacht, want sommige moedertaalsprekers van het Nederlands zullen er niet direct in meegaan; za[gd]oek is niet de algemene, onvermijdelijke uitspraak - zakdoek valt in de categorie woorden die op meerdere manieren worden uitgesproken, waarbij beide vormen redelijk ongemarkeerd kunnen zijn, zoals tan[d]arts versus tan[t]arts, en waarvan de uitspraak met de aard van lopende spraak samen kan hangen. Er is een verschil tussen iets vaak gehoord hebben en systematisch iets menen te horen. Dat onderscheid wordt op de pagina's niet altijd duidelijk gemaakt, onder andere voor assimilatieverschijnselen. 


\section{Sociofonetische variatie}

In het bovenstaande is enkele keren gerefereerd aan de relevantie van sociale en situationele informatie in de beschrijving van uitspraak. De vele sociolinguïstische onderzoeksresultaten die beschikbaar zijn hierover vormen nuttige bronnen voor mensen die de taal beter willen leren kennen, als leerder dan wel als onderzoeker. De realiteit van uitspraak kan dus gevolgd worden door inzichten in de sociale distributie van varianten.

Als motivatie voor het bestaan van de website wordt gegeven dat 'language is seen as an important part of cultural identity and cultural heritage'. Dit geeft aan dat er interesse bij de makers is voor culturele en sociale aspecten van taal. De website geeft verder aan dat 'Dutch is considered a pluricentric language with different (developing) standards in The Netherlands, Belgium and Surinam, and also in Aruba, Curaçao, and Sint Maarten'. Een apart gedeelte over variatie binnen het Nederlandse taalgebied, dat middels deze opmerking is uitgebreid naar overzeese, Zuid-Amerikaanse gebieden, lijkt op zijn plaats. Vooral het zuidelijk Standaardnederlands verdient aandacht. Onderzoek van Van de Velde (1996) en Adank et al. (2004) suggereert dat de noordelijke en zuidelijke taalnormen eerder uit elkaar aan het groeien zijn wat betreft de uitspraak dan dat ze naar elkaar toegroeien, zoals vaak over de grammatica wordt gezegd, en zoals de Algemene Nederlandse Spraakkunst lijkt te willen uitstralen. Ook de variatie binnen dialecten in het gehele Nederlandse taalgebied verdient meer systematische aandacht, en wel zonder dat de landsgrenzen als harde scheidslijn worden gehanteerd.

Ook op fonemisch niveau is een stuk sociale achtergrond over varianten en frequentie nuttig. Een voorbeeld is de opmerking dat Utrecht getranscribeerd dient te worden als /ytrext/ maar dat [ytrex] als substandaard en regionale variant ook voorkomt. Ander voorbeelden zijn: 'Younger speakers of Northern Standard Dutch may have a wider diphthong, towards [æi]' en 'Younger speakers of Northern Standard Dutch may have a wider diphthong with an unrounded first element, towards [BY]'. Menig geïnteresseerde lezer wil meer weten over de systematiek achter sociale variatie, vooral als een bepaalde variant in de normtaal gebruikelijk is. Lichte verlaging van het eerste element van de drie tweeklanken in de Nederlandse normtaal is bijvoorbeeld eerder een regel dan uitzondering, en de tweede $t$ in Utrecht niet uitspreken is mogelijk minder wijd verbreid (en interessant) dan gesuggereerd wordt en niet geheel ondenkbaar in de snel uitgesproken normtaal. 


\section{Redactie}

Wat jammer is, maar makkelijk te verhelpen, is een bepaalde redactionele onrust in de pagina's. De lezer komt in het fonologiegedeelte een aantal spel-/taalfouten tegen in relatief weinig tekst. De namen van de contributors zijn soms wel en soms niet voorzien van een foto, van een voornaam, en/of van een cv, en er staat een enkele spelfout in de namen. Niet alle contribuanten staan in de lijst. Enkele academische titels kloppen mogelijk niet meer. Sommige inhoudelijke teksten zijn genummerd, andere weer niet. Onder het kopje Waarom Engels? ontbreekt een Friese vertaling.

Het gebruik van voorbeeldwoorden in de teksten is niet altijd consequent. Zo staat er: 'the word for car is [auto] for some speakers and [oto] for others'. Van buitenlanders kan niet verwacht worden dat ze weten wat het Nederlandse woord voor vierwielig motorvoertuig is, waarbij de spelling relevant is, en ook is het verwarrend als het Engelse woord car niet onderstreept is of cursief gedrukt, zodat duidelijk is dat het een voorbeeldwoord is. Op andere plekken staan er wel vertalingen bij en wordt vet gebruikt om een voorbeeld te highlighten.

De onrust wordt versterkt door de afbeelding van het menselijk spraakorgaan die gegeven wordt. Het plaatje, 'adapted from' het handboek van de International Phonetics Association uit 2011, is slordig getekend en gescand, en er staan verwarrende dingen in. Al met al is deze afbeelding eigenlijk overbodig omdat er online zoveel goede beschikbaar zijn die al zulke algemene informatie geven die niet specifiek is voor het Nederlands. Voor de klinkers wordt een diagram gegeven dat specifiek is voor het Nederlands maar het uitspraakhoofd is meer algemeen beschrijvend, wat inconsequent lijkt.

Klinkerdiagrammen zijn verder gegeven voor de noordelijke en zuidelijke variant van de Nederlandse normtaal, maar deze opdeling wordt voor de medeklinkers niet gemaakt. Of bepaalde informatie algemeen is of specifiek voor een taal is niet altijd even duidelijk, wat ook zichtbaar is in de articulatorische beschrijving van fonemen. Voor /p/ is dit bijvoorbeeld: 'A possible feature specification of $/ \mathrm{p} /$ is -sonorant, -voice, +labial, -coronal, -velar, continuant'. Hierbij kan misschien duidelijk gemaakt worden of dit een algemene beschrijving is van de /p/, zoals die in een algemene inleiding in de fonetiek gegeven zou kunnen worden, of dat dit een beschrijving is van de specifieke Nederlandse /p/. Eventueel kan alleen een beschrijving worden gegeven als er discrepanties zijn, en er kan een verwijzing worden gegeven naar algemene informatie die gewoon online beschikbaar is.

Ten slotte is er een bepaalde inconsistentie waar het de inhoud van tekst betreft. De ene auteur geeft veel informatie die de kern overstijgt, terwijl de andere zich strikt houdt aan 
de opdracht. Dat betekent dat wanneer over soortgelijke onderwerpen door meerdere auteurs geschreven is, de mate van detail en uitweiding varieert.

\section{Algemene opmerkingen over de website}

\subsection{Keuze voor de drie behandelde talen}

Een logische verantwoording van de keuze voor de drie talen zou goed zijn. Deze keuze is niet helemaal duidelijk na het gedeelte onder het welkomstwoord en de Aims. Er wordt gewezen op de culturele relevantie van taal in het algemeen en het feit dat mensen het Nederlands, Fries en het Afrikaans vaak als tweede taal leren. Echter, deze en de andere redenen gaan ook op voor andere talen. Van taalkundigen in de wereld kan niet verwacht worden dat ze de historische en taalkundige verbondenheid van deze drie talen kennen. Wat niet helpt, is dat op de website de ene keer verwezen wordt naar Taalportaal als een grammatica van genoemde drie talen, terwijl elders op de website de suggestie wordt gewekt dat alleen het Nederlands behandeld wordt. De onduidelijkheid over de drie talen wordt versterkt doordat er op de algemene pagina van Taalportaal een afbeelding verschijnt waarop met boogjes een verband wordt gelegd tussen het Fries en het Afrikaans en tussen het Nederlands en het Afrikaans. Dit kan misschien uitgelegd worden. Vooral de boog tussen het Fries en Afrikaans roept om uitleg.

\subsection{Aard van de taalkundige beschrijving}

Wat is de precieze definitie van 'the grammars of' en 'the linguistics of'? De suggestie wordt open gelaten dat deze twee typeringen gelijk zijn. De website zegt de 'phonology, morphology and syntax' van de drie talen te beschrijven, maar dat is geen volledig taalkundige beschrijving. Het lijkt vooral een theoretische grammaticabeschrijving. Er is weinig systematische aandacht voor variatie op gebruiksniveau, terwijl bijvoorbeeld fonetische variatie ook onderdeel is van de linguistics van de drie talen.

\subsection{Totstandkoming van de inhoud}

Er zijn veel aanwijzingen dat de website bovenal een Nederlandse aangelegenheid is. De betrokken instituten en partners hebben een hoog Nederland-gehalte en ook een blik op de contribuanten bevestigt deze Nederlandse, en in iets mindere mate ook Zuid-Afrikaanse saus. In de lijst van Contributors kan ik geen medewerker van een Vlaams instituut vinden. De samenstelling van het achtkoppige team dat Dutch Phonology beschrijft, bestaat uit vijf Nederlanders en drie Duitsers. Voor de naïeve lezer kan dit suggereren dat in Vlaanderen 
geen medewerking wordt verleend dan wel dat het Nederlands in Nederland meer aandacht verdient dan het Nederlands in Vlaanderen, of misschien dat de verschillen verwaarloosbaar zijn. De website geeft wel aan dat de keus om alleen het Noordelijke Nederlands te beschrijven '[f]or the time being' is, waarmee in ieder geval wordt gesuggereerd dat zo'n bijdrage belangrijk is en de inhoud ook zou kunnen beïnvloeden. Maar dat dit slechts als toekomstige optie wordt gegeven, geeft een lagere status aan het Nederlands in Vlaanderen. Een en ander laat de indruk achter dat er weinig bewustzijn is bij de websitemakers van de gevoeligheid die in Vlaanderen heerst als het de Nederlandse taal betreft, en over hoe Nederlanders met die gevoeligheid omgaan.

De inhoud zou explicieter kunnen worden verantwoord. Hoe verhoudt deze website zich precies tot Taalunieversum, de Algemene Nederlandse Spraakkunst en de Syntax of Dutch? Er staat hierover al wat informatie, maar deze zou misschien uitgebreider en systematischer kunnen, vooral ook daar de grammatica in Taalportaal als 'authoritative' wordt gekwalificeerd. Hoe is de keuze van auteurs/vertalers tot stand gekomen? Wordt er een soort Wikipedia-achtig systeem aangehouden om teksten te updaten? Uitleg van de precieze rol van contribuanten (individuen en groepen) zou ook nuttig kunnen zijn. Naast de 32 inhoudelijke Contributors, zijn er 46 andere medewerkers, die verdeeld zijn over zeven verschillende boards. Wat de verschillen zijn tussen sommige boards is niet geheel duidelijk, en men vraagt zich af hoe de onderlinge communicatie tussen groepen, subgroepen en individuen is, vooral bij het bepalen van de uiteindelijke inhoud.

\subsection{Naamgeving}

De naamgeving van de website is ongelukkig. Kwalificaties als 'language portal' en de naam Taalportaal zelf suggereren voor sommigen misschien iets anders dan de inhoud, namelijk een bron van kennis over taal of een reeks talen, niet over een drietal aan elkaar verwante talen. Een ander probleem is dat de samenstelling Taalportaal Nederlandstalig lijkt en dat bevestigt het gevoel dat de pagina vooral een Nederlands initiatief is. Waarom geen Engelstalige websitenaam? De naam Taal Portal zou misschien beter zijn, omdat deze automatisch verwijst naar genoemde drie talen (Taal is hetzelfde in het Nederlands, Fries en Afrikaans) en voor de rest Engelstalig is (Portal). Die suggestie tot naamverandering hangt ook samen met de observatie dat er meerdere taalportaalpagina's online zijn: Er is nu een taalportal.org, een taalportaal.be, een taalportaal.com, en een taalportaal.nl. Universiteiten en uitgeverijen zitten achter deze websites. De meeste gebruikers van deze term brengen het in verband met vreemde-taalverwerving door Nederlandstaligen. 


\section{Suggesties}

Het fonologische gedeelte in het Taalportaal ziet er goed uit, los van wat makkelijk te verhelpen inconsistenties en onregelmatigheden. Ik denk dat de pagina's erbij gebaat zouden zijn als ze aangepast werden op het beoogde lezerspubliek, en er daarbij niet vanuit wordt gegaan dat dat publiek de basis van de taal al kent. Taalkundigen buiten het Nederlandse taalgebied en met geen kennis van de taal die toch het Nederlands verder willen ontdekken, zijn gebaat bij een nog uitgebreidere, meer bottom-up beschrijving en bij meer illustratie en uitleg. Veel van de tekst is duidelijk geschreven voor en door een ingroep aan fonologen die genoeg hebben aan weinig en beperkte informatie, en dat terwijl het Taalportaal meldt dat de pagina's ook nuttig zijn voor 'users less versed in linguistic theory' en 'people dealing with language and grammar in a more practical way, such as teachers, language advisors and authors developing teaching materials'. Voor de gemiddelde taalkundige in een land ver weg, met een moedertaal die niet Germaans is, is de fonologische beschrijving echter minder toegankelijk. Voor docenten taalvaardigheid zijn de beschrijvingen misleidend omdat zij de werkelijke uitspraak willen weten. Wanneer beschrijvingen algemeen fonologisch zijn of niet, welke varianten van het Nederlands bedoeld worden, wat mogelijke intra- en intersprekervariatie is, welke sociale, regionale en andersoortige varianten er überhaupt zijn; die dingen moeten niet slechts anekdotisch worden vermeld.

Uitgelegd kan worden waar de theoretisch grammaticale beschrijving ophoudt, zodat de nu nog losse opmerkingen over variatie beter tot hun recht komen. De taalvariatiesituatie kan worden uitgelegd en hoe deze de werkelijke uitspraak in bepaalde situaties en door bepaalde sprekers beïnvloedt, zelfs situationeel. Regionale variatie kan moeilijk los worden gezien van sociale en situationele variatie. Voor een noodzakelijke beschrijving zouden extra auteurs aangesteld moeten worden, vooral ook om de situatie in Vlaanderen en die in de overzeese Nederlandstalige gebieden te beschrijven. Als de websitemakers dit soort detail te ver vinden gaan, en als ze deze informatie niet meer vinden thuishoren in een grammatica of vallen binnen 'the linguistics of', dan zou kunnen worden volstaan met verwijzingen naar de vele Engelstalige publicaties over de Nederlandse taalvariatiesituatie om op die manier ruimte te geven aan taalkeuzes van groepen en individuen. Het interactieve aspect in van het Taalportaal zou uitgebreider kunnen. Links binnen en buiten de website lijken me niet een teken van interactiviteit. Interactiviteit suggereert een interactie tussen maker en gebruiker. Om interesse in de Nederlandse taal te versterken, zou de website wat moderner en aansprekender kunnen worden en werkelijk interactief. Geluidsclips voor alle woorden en 
klanken die genoemd worden, zouden toegevoegd kunnen worden. Videoclips waarin taalkundigen in hun eigen bewoordingen een fonologisch fenomeen verder uitleggen en demonstreren, zouden de pagina's nog aantrekkelijker maken. Er zou ruimte kunnen komen waarin gebruikers een vraag zouden kunnen posten die dan door de auteur online beantwoord wordt, zodat een lijst met FAQs gemaakt kan worden. Een Suggestions for further reading, viewing, and listening die naar externe bronnen verwijst, met allerhande geschikte links en andere bronverwijzingen, zou heel nuttig zijn. (Van de huidige Suggestions for further reading zou misschien See also kunnen worden gemaakt, want het betreft interne verwijzingen.) Er zijn veel Engelstalige referenties en filmpjes beschikbaar over de verschillende thema's, en de auteurs zouden zelf een selectie kunnen maken van de beste van die bronnen. Veel van die bronnen zijn online vrij beschikbaar en in dat geval zou de url gegeven kunnen worden.

\section{Referenties}

Abercrombie, D. (1964). English Phonetic Texts. London: Faber and Faber.

Adank, P., R. Van Hout \& R. Smits (2004). An acoustic description of the vowels of Northern and Southern Standard Dutch. The Journal of the Acoustical Society of America 116, 1729-1738.

Bilderdijk, W. (1826). Nederlandsche Spraakleer. 's Gravenhage: J. Immerzeel, jr.

Botma, B., K. Sebregts \& D. Smakman (2012). The phonetics and phonology of Dutch midvowels before /1/. Laboratory Phonology 2, 273-299.

De Vooys, C. G. N. (1946). Nederlandsche spraakkunst. Groningen/Batavia: J.B. Wolters.

Eggermont, C. \& M. D'hoedt (2012). Taalportaal: een elektronisch platform voor taalvaardigheidstraining op maat. In: D. Smakman \& L. Willemsen (red.), Van Schools tot Scriptie. Een colloquium over universitair taalvaardigheidonderwijs. Leiden: Leiden University Repository.

Gussenhoven, C. (1981a). Measuring the acceptability of voiced fricatives in Dutch. Proceedings of the Institute of Phonetics of the Catholic University of Nijmegen 5, 96129.

Gussenhoven, C. (1981b). Voiced fricatives in Dutch: sources and present-day usage. Proceedings of the Institute of Phonetics of the Catholic University of Nijmegen 5, 8495.

Gussenhoven, C. (1992). Dutch. Journal of the International Phonetic Association 22, 45-47. 
Gussenhoven, C. (2007). Wat is de beste transcriptie voor het Nederlands? Nederlandse Taalkunde 12, 331-350.

Kloots, H. (2008). Vocaalreductie in het Standaardnederlands in Vlaanderen en Nederland. Delft: Eburon.

Mees, I. \& Collins, B. (1982). A phonetic description of the consonant system of Standard Dutch (ABN). Journal of the Internation Phonetic Association 12, 2-12.

Sebregts, K. (2014). The Sociophonetics and Phonology of Dutch /r/. Proefschrift Utrecht University.

Smakman, D. (2006). Standard Dutch in the Netherlands. A Sociolinguistic and Phonetic Description. Utrecht: Landelijke Onderzoeksschool Taalwetenschap (LOT).

Stroop, J. (1998). Poldernederlands. Waardoor het ABN Verdwijnt. Amsterdam: Bert Bakker.

Van de Velde, H. (1996). Variatie en Verandering in het Standaard-Nederlands (1935-1993). Utrecht: Landelijke Onderzoeksschool Taalwetenschap (LOT).

Van der Wal, M., \& Van Bree, C. (2008). Geschiedenis van het Nederlands [The history of the Dutch language]. Utrecht: Het Spectrum.

Van Haeringen, C. B. (1924). Eenheid en Nuance in Beschaafd-Nederlandse uitspraak. In: C. B. Van Haeringen (red.), Neerlandica. Verspreide Opstellen (8-30). 's Gravenhage: D.A. Daamens Uitgeversmaatschappij N.V., 65-86.

Zwaardemaker, H. \& L. Eijkman (1928). Leerboek der phonetiek - inzonderheid met betrekking tot het Standaard-Nederlandsch. Haarlem: De Erven F. Bohn.

\section{Over de auteur}

Dick Smakman, Centre for Linguistics, Universiteit Leiden.

E-mail: $\underline{\text { d.smakman@hum.leidenuniv.nl }}$ 